\title{
Assessing Teaching Format as it Applies to Motivation and Perceptions of Teaching and Learning in Geological Sciences Education
}

\author{
William R. Merchant ${ }^{1, *} \&$ David Dees ${ }^{2}$ \\ ${ }^{1}$ The University of Northern Colorado, USA \\ ${ }^{2}$ Kent State University, USA \\ *Correspondence: The University of Northern Colorado, USA. E-mail: \\ William.merchant@unco.edu
}

Received: August 19, 2017 Accepted: September 13, 2017 Published: September 29, 2017

doi:10.5296/ije.v9i3.11725 URL: https://doi.org/10.5296/ije.v9i3.11725

\begin{abstract}
Objective: This study sought to compare the motivation and classroom level perceptions of students participating in three different classroom formats (i.e. lecture only, data/lecture, lab/data/lecture). Method: A Multivariate Analysis of Variance (MANOVA) was used to compare subscales from the Motivation Strategies and Learning Questionnaire (MSLQ) and Experiences of Teaching and Learning Questionnaire (ETLQ) across the three teaching formats. A correlational analysis was then conducted examining relationships within and between MSLQ and ETLQ subscales and select student outcomes. Results: Teaching format was not found to be a significant factor in relation to student motivation or class level perceptions except for the perception of choice which was higher for the lecture only format. A strong collection of correlations suggest that classroom and teacher level variables are positively related to deep learning. Conclusion: This study found that class format is not as impactful on student level outcomes as is their perception of the learning environment and teacher interactions.
\end{abstract}

Keywords: Motivation, Perceptions of teaching, Geological education 


\section{Introduction}

The quality of a student's learning environment is often a direct predictor of student achievement and success. If this is the case, how then does variation in classroom approach influence student achievement outcomes and other factors that have been proven to be impactful to student success, such as motivation and perceptions of teacher and program quality? The aim of this study is to examine such variations in classroom format in the form of three distinct teaching approaches to see how they relate to important student level measures of motivation, learning approach, and perceptions of class demands and knowledge acquired. In order to accomplish this, a collection of measures were administered to students in North East Ohio over the span of five semesters as three professors alternated their teaching approaches between three specific methods (i.e. lecture only, lecture and data, and lab/lecture/data). The primary surveys used in these analyses were the The Experiences of the Teaching and Learning Questionnaire (ETLQ) and Motivation Strategies and Learning Questionnaire (MSLQ)

\subsection{Overview of learning and course perception constructs}

In order to maximize student outcomes, research has long been underway to uncover the specific ways in which students learn (Entwistle, McCune, \& Hounsell, 2003; Entwistle \& Ramsden, 1983; Fraser, 2015)Marton, Hounsell, \& Entwistle, 2015; Marton \& Säljö, 1976; Parpala, Lindblom-Ylänne, Komulainen, Litmanen, \& Hirsto, 2010). Development of the constructs that compose the ETLQ and MSLQ began with research conducted by Marton and Säljö (1976) suggesting that there were two primary ways in which students gathered and assimilated knowledge using surface and deep learning approaches. Those who employ deep learning were more apt to be learning at a comprehensive internalizing level, while those who use surface learning tend to memorize information for the purposes of answering anticipated assignments and exams. Since the establishment of these concepts they have since been referred to as deep and surface approaches to learning in the literature (Marton \& Säljö, 1984).

Beyond surface and deep approaches, it was also observed that many, if not all students were aware of the assessments by which they themselves are evaluated. As such, student's often make adjustments to how and what they study. This perspective was named the strategic (Entwistle \& Ramsden, 1983) or achieving approach (Biggs, 1987) to learning. More recently, research on approaches to learning have referred to these as organized studying or organized effort in studying, which emphasize time management, self-regulation and effort in studying (Entwistle \& McCune, 2004). Furthermore, when the deep approach to learning is combined with organized studying, better learning outcomes are observed (Entwistle \& Ramsden, 1983; Lindblom-Ylänne, 1999).

Beyond purely student-centered efforts towards learning, perceptions of the teaching-learning environment are also related to student outcomes and learning strategies. In 2003 Entwistle, McCune and Hounsell identified course design and organization, teaching and assessing, staff-student relationship, and peer support as being integral to the concept of a teaching-learning environment that supports student quality learning. Research has shown 
that perceptions of high quality teaching-learning environments are positively related to the deep approach to learning and negatively related to the surface approach (Entwistle \& Tait, 1995; Richardson, 2005; Richardson \& Newby, 2006). One potential interpretation of this relationship is that students who favor a deep approach to learning tend to be more involved in the learning process and therefor perceive more positive qualities in the learning environment. An alternative interpretation is that it is the learning environment that fosters a deeper approach to learning. One example of this student environment interplay could be observed as positive perceptions of teaching being positively related to the deep approach to learning and negatively related to the surface approach to learning (Diseth, 2007a; Diseth, 2007b; Prosser \& Trigwell, 1999).

Student level learning approaches and classroom perceptions, teaching approaches can also be conceptualized based on constructive alignment, which refers to the intersection of learning objectives, teaching methods, and assessment (Biggs, 2003). This constructive alignment has also been found to be associated with greater frequency of the deep approach and in turn, higher quality student learning (Biggs, 1999). Research has shown that students' perceptions of alignment in teaching are a good indicator of this construct and are similarly associated with the deep approach to learning (Parpala et al., 2010). The ways in which students perceive a supportive peer environment have also been seen to be an impactful factor on learning (Rytkönen, Parpala, Lindblom-Ylänne, Virtanen, \& Postareff, 2012). Perceptions of stronger social support networks are also positively related to the deep approach and negatively related to the surface approach (Entwistle et al., 2003; Parpala, Lindblom-Ylänne, Komulainen, \& Entwistle, 2013).

While student learning approaches and perceptions of both teaching and the learning environment are well established, student motivation is also an integral component of student success. Included in this study is the Motivated Strategies and Learning Questionnaire (MSLQ) which is a self-report measure, created to assess college students' motivational orientations and their use of various leaning strategies. This assessment differs from other measures of motivation and learning strategies in that it conceptualizes instructional input as being mediated by student beliefs and cognitions about motivation and learning approaches (Pintrich, 1988).

The MSLQ's motivation subscales are centered around three different motivation constructs (Pintrich, 1988, 1988b); they are motivation related to expectancy, value, and affect. The expectancy factor refers to a student's beliefs that they can successfully complete a task. There are two expectancy-related subscales which include perceptions of self-efficacy and control beliefs for learning. The value components of motivation focuses on the reasons why students participate in various academic tasks. Three value components make up this section of the MSLQ, they include intrinsic goal orientation (i.e. a focus on learning and mastery), (2) extrinsic goal orientation (i.e. a focus on grades and approval from others), and task value beliefs (i.e. judgements of how interesting, useful, and important the course content is to the student).

The MSLQ also contains some learning strategies which are based on a general cognitive 
model of learning and information processing (Weinstien and Mayer, 1986). There are three general types of scales: (1) cognitive, (2) metacognitive, and (3) resource management. For the purposes of this research only the critical thinking subscale or learning strategies was is included. This scale evaluates the students' use of strategies to (a) apply previous knowledge to new situations and/or (b) make critical evaluations of ideas.

\subsection{Rationale}

This study employed a mixed methods design in which student self-report ratings of learning style, class room quality perceptions, and motivation were compared with academic outcomes as they differed across classroom format and class standing. To further discover the key factors related to student success, qualitative focus groups and interviewing were also conducted. The goal of these follow up sessions were to inform and increase the depth of understanding provided by this study. Overall, this design allows for both measurable outcomes to be analyzed and for the student voice to come through as participants revealed information about their personal subjective experiences in the courses.

\section{Procedures}

\subsection{Sampling}

Participants were recruited across five semesters spanning three academic years. Because both classroom format and teacher influence were considered to be meaningful grouping variables, data was collected using a quasi-experimental classroom and format based method. In order to ensure that class format could be analyzed after accounting for specific teacher effects, each professor taught each format at least once.

At the beginning of each course students were given a brief overview of the research and invited to participate. Those who elected to participate then completed the LSQ, MSLQ, and general demographic data, which included information related to gender, class standing, major, and GPA. Over the span of the semester, student grade data was also collected. At the end of each semester the ETLQ and MSLQ were administered again. Furthermore, focus groups were conducted at the end of each semester with students to gather qualitative insights related to their experiences.

\subsection{Demographics}

A total of 183 students were surveyed over the course of this program. The majority of the participants were undergraduate students $(n=125,69 \%)$, followed graduate students $(n=56$, $31 \%$ ). The sample was fairly evenly split by gender (Male, $n=93,51 \%$; Female, $n=91$, $49 \%$ ). Information was gathered from students across five different classes; including Environmental Geochemistry, Paleoceanography, Sedimentology and Stratigraphy, Urban Hydrology, and Watershed Hydrology.

\subsection{Instrumentation}

ETLQ. The Experiences of Teaching and Learning Questionnaire (ETLQ) measures the 
learning approaches that students have used during a particular course unit and their perceptions of the teaching- learning environment. It is a self - report that can be completed in person at the beginning or end of a class. The first section measures Approaches to Learning and Studying and contains 18 items with four scales related to how students have studied the course unit: deep approach (6 items); surface approach (4 items); monitoring studying (4 items); and organized studying (4 items).

The second section, Experiences of Teaching and Learning, contains 40 statements across 11 scales concerned with how they perceived the course unit. The subscales of this section are organization and structure (3 items); alignment (3 items); integration of teaching and learning (3 items); choice ( 2 items); encouraging high quality learning (5 items); clarity of feedback about assessments (5 items); assessing for understanding (4 items); staff enthusiasm and support (4 items); support from other students (3 items); and interest, enjoyment, relevance (5 items). All items in this section were scored on a 5 - point scale ranging from "disagree" (coded as 1) to "agree" (coded as 5).

The third section contains 10 items related to the demands made by the course unit; scores are tallied using a 5 - point scale with "very difficult" (coded as 1) and "very easy" (coded as 5). The fourth section contains 8 items asking students to rate their knowledge gained; they rate each outcome on a 5 - point scale ranging from "very little" (coded as 1) to "a lot" (coded as 5). Lastly, there is one item that asks how well students feel they have done in the course unit overall. They respond on a 9 - point scale from "rather badly" (coded as 1) to "very well" (coded as 9). Scores are assigned on each scale as the mean of the coded responses to its constituent items.

MSLQ. The original version of the MSLQ is designed to be given in class and takes approximately 20-30 minutes to administer. It contains two components, student motivation and learning strategies. The original 81 items are scored on a 7-point Likert scale from 1 (not at all true of me) to 7 (very true of me). The motivation section consists of 31 items that assess the students' goals and value beliefs for a course, their beliefs about their skills to succeed in a course, and their anxiety about tests in a course. The learning strategy section includes 50 questions: 31 items regarding students' use of different cognitive and meta-cognitive strategies and 19 items concerning student management of different learning resources. For the purposes of this research, only items related to intrinsic, extrinsic, and task value scales from the motivation section, and critical thinking from the learning strategies potion of the MSLQ were used.

Scores were constructed by taking the mean of items the make up the scale. Negatively worded item scored were revered before individual scores were computed. The statistics reported here represent the positive wording for each of the factors meaning that higher values indicate a greater presence of that construct.

\subsection{Data analysis}

The mixed method approach of this study employed three Multiple Analysis of Variance (MANOVA) analyses to compare student level outcomes across class standing, class format, 
and instructor. MANOVA is a statistical technique used to compare two or more groups across more than one outcome variable. Comparisons were made across all ETLQ and MSLQ subscales, motivation change scores between the beginning and end of the semester, and student achievement outcomes such as final course grade, semester knowledge growth, and GPA between the class format groupings (i.e. Lecture only, Data lecture, lab data lecture), and class standing (undergraduate, graduate) and between the three professors. Additionally, a correlational analysis was conducted to observe the relationships that occurred between the key metrics used with the students. After the quantitative data was collected, a series of focus groups were conducted with student volunteers in an attempt to allow the student voice to influence the interpretation of our quantitative analyses.

\section{Results}

\subsection{MANOVA}

A MANOVA was used to compare posttest learner motivation, grade, and perception of the course as it occurred across classes grouped by teacher, and teaching technique. When all classes were included in the comparison, there appeared to be significant differences between the "Hands-on + Data + Lecture" class, and the remaining two conditions (Data + Lecture and Lecture Only), with "Hands-on + Data + Lecture" scoring lower on perceptions of choice, staff enthusiasm and support, and change in perception of task value related to course material $(\mathrm{p}<.05)$. Motivation based on intrinsic factors, control, task value, and self-efficacy also significantly decreased for all classes over the course of the semester.

Based on a report that one of the classes appeared to be an anomaly due to logistical factors that may have influenced student evaluations, this one class was removed and the above analysis was conducted again. After this change, no significant differences remained, except one indicating that students perceived that they were given more of a choice with regards to the direction of the class during the Lecture only class, than in the Data + Lecture format ( $p$ $<.05)$. When teachers were evaluated against each other and themselves across different semesters there were no significant differences on any of the measured factors.

\subsection{Correlation}

After this, a correlational analysis was conducted to explore any relationships between variables that might have an impact on student learning, motivation and perception. These results indicate that there is a strong "logistical" factor composed of items related to perceptions of class organization, alignment with teaching goals, and integration of teaching materials, which were highly correlated with perceptions of staff enthusiasm and support, and personal interest in class material. The use of surface learning techniques is also moderately negatively correlated with the logistical factor, perceptions of interest, staff support, interest, clarity, and strongly negatively correlated with self-efficacy. Self-efficacy was strongly correlated with intrinsic motivation, perception of task value, and motivation based on control of one's performance in class. 


\subsection{Class standing comparison}

Ratings in perception and motivation were also compared between students grouped by class standing. This resulted in finding no significant differences at posttest between graduate and undergraduate students. The groups did differ significantly a pretest though, with undergraduate students entering the class with significantly lower GPA and higher ratings of taking the course for extrinsic or externally motivated reasons. Students were then divided into groups by senior, graduate student, or freshman through junior status. This comparison found seniors and graduate students began their classes with significantly higher ratings of effort and self-monitoring approaches to their learning. At posttest both senior and graduate students reported significantly higher self-ratings of using an organized approach towards the course, and graduate students had higher ratings of interest in course material than freshman through junior student groups.

\subsection{Qualitative focus groups}

A series of three focus group interviews were organized with student volunteers. These focus groups were conducted during the academic semester following participating course sections. Two of the focus groups were conducted during the Fall 2013 semester and one was conducted during the Spring 2014 semester. A total of thirteen different students (14 total) have participated in these ninety minute discussions. One undergraduate student participated in discussions for two different classes. This has included 8 graduate students $(6$ females and 2 males) and 5 undergraduate students ( 2 females and 3 males).

The primary purpose of these interviews was to cross reference the quantitative data and to also identify any other significant issues within each class. Thematic analysis of each of the interviews has been conducted by one of the researchers and member checking was used to verify the selected themes. There are two predominant themes that directly address and verify the quantitative data. Students in these interviews all agreed that, regardless of the class, motivation is at the lowest at the end of the semester. Additionally, all students agreed that their approach to learning was not shifted in any significant manner during these course experiences.

However, during these interviews, other themes did arise that are of interest to this study. First, when asked what could be done to increase motivation during a semester, the students noted that being able to see change over time adds to their motivation. For example, courses that allow students to document their learning throughout the semester and then reflect back at the end to note their change in thinking tends to increase their motivation at the end of the semester. Reflecting back on the change in their learning was reported as important.

In terms of changing the way the students approach learning, how they are assessed in the most significant factor. Several of the students discussed that their current approach to studying has worked for them throughout their academic career. As they noted, the way they are typically assessed encourages the approach they currently have adopted. However, they noted that when faculty assess them in different ways, for example asking to use more of an inquiry approach, students will adjust the way that they study and think about the course 
material.

Finally, the most significant factor that influences their approach to a class and/or learning is professor passion. All of the groups noted that professor passion, highlighted by inquiry-based questions, increased vocal inflection and body movement, and deep sense of care for student learning, is the most significant element that will change the way they think about the material and approach the class.

\section{Discussion}

Overall interpretation of the quantitative analyses revealed a collection of compelling results. The first analysis of motivation change from the time that occurred between the beginning of the semester and the end revealed that all students reported a decrease in motivation across all settings at the end of the semester. While this is an interesting outcome, it brings with it a few key observations. The first being that no matter what the class format, students began their studies with higher levels of motivation than they did at the end of the semester. Secondly, this drop in motivation was not influenced by class format, class standing or instructor.

Additionally, there were no differences between class format on any of the learning styles, or classroom/teacher perceptions with the exception of the perception of choice, in which the lecture only class scored higher than the lecture + data format. One interpretation of this finding suggests that students perceive greater choice over the direction of the class during lecture only formats largely due to the opportunity for them to ask questions rather than only being allowed to follow the direction of the data analysis procedure.

Furthermore, the correlation analysis revealed that there was a strong relationship between the classroom factors (organization, perception of choice, integration, encouragement, etc.) with perceptions of staff. The strong interplay of these classroom perception factors and their interplay with perceptions of staff indicate that even minor variations in one component are likely to shift one's interpretation of the global "classroom" factor, bringing with it perception of instructor quality.

Regardless of the impact of this classroom factor and the overall decrease in student motivation, students demonstrated statistically significant increases in their content learning across all teaching styles as measured by course appropriate pre and post tests. Furthermore, all students demonstrated the same level of academic content growth regardless of instructor. Teaching style was also not found to be a key determinant of learning style or classroom perception. In summary, if motivation universally decreased over the course of the semester, class format did not have an effect on student learning style and perception, and all instructors measured the same amount of student knowledge growth, what are the professor and classroom level components that actually do have an impact on student learning, perception, and growth?

Our correlational analysis revealed that self-efficacy was significantly related to approach to learning. Specifically, those with higher levels of self-efficacy as measured by the MSLQ had 
greater occurrences of the deep learning approach and less surface learning. Additionally, surface learning was negatively correlated with measures of self-rated perceptions of mastery and understanding, and final course performance evaluation in the form of final exams and class grades. Furthermore, Intrinsic motivation as measured by the MSLQ was highly positively correlated with perceptions of class activity, material task value, and critical thinking.

The qualitative portion of this study mirrored many of the quantitative results. Student participants reflected on the fact that experiential based lab exercises are not the key components in gauging course quality and learning but are somewhat expected in this field. One student stated:

"Labs can be either good or bad....it matters what the point is and how they are conducted...."How else could you teach Geology?"

Focus groups also confirmed that students felt a decrease in motivation towards the end of the semester but also suggested that having opportunities to look back at their knowledge levels at the beginning of the semester was a meaningful exercise to demonstrate how far they had come over the span of the course. They also confirmed that how they were tested changed the ways that they studied and approached course material (MSLQ strategic approach). Overall students agreed that teacher passion was the single most impactful factor related to their motivation, perception, and evaluation of the course and teacher. These results suggest that teachers, irrespective of course resources and class format, try to find a way to enliven their own passion related to the subject which in turn, spreads to student level outcomes.

\section{Limitations}

One potential limitation of this study is that all student level measures were self-reported. Self-reported data has the potential to be skewed towards the responded competing answers so that he or she is viewed in a more favorable light. The items used in this study do not reveal student level traits so the ability for one to select more favorable options is decreased. This study also only utilized a sample from one institution using only students studying in the field of geology. Further research should be conducted to observe if other disciplines may perceive classroom variations in different manners.

\section{Conclusion}

Overall, the results of this study suggest that it is not class format that influences student motivation and class perceptions but rather an interconnected network of environmental and interpersonal variables at the instructor and coursework levels. These findings indicate that in order to increase student learning and motivation faculty focus on their interactions with students and the organization of course work and class activities. 


\section{References}

Biggs, J. B. (1987). Student Approaches to Learning and Studying. Research Monograph. Australian Council for Educational Research Ltd., Radford House, Frederick St., Hawthorn 3122, Australia.

Biggs, J. (1999). What the student does: Teaching for enhanced learning. Higher education research \& development, 18(1), 57-75. https://doi.org/10.1080/0729436990180105

Biggs, J. (2003). Aligning teaching and assessing to course objectives. Teaching and learning in higher education: New trends and innovations, 2, 13-17.

Diseth, Å. (2007). Approaches to learning, course experience and examination grade among undergraduate psychology students: Testing of mediator effects and construct validity. $\begin{array}{llll}\text { Studies in } \quad H i g h e r & \text { 37ucation, 32(3), 388. }\end{array}$ https://doi.org/10.1080/03075070701346949

Diseth, Å. (2007). Students' evaluation of teaching, approaches to learning, and academic achievement. Scandinavian Journal of Educational Research, 51(2), 185-204. https://doi.org/10.1080/00313830701191654

Entwistle, N., McCune, V., \& Hounsell, J. (2003). Investigating ways of enhancing university teaching-learning environments: Measuring students' approaches to studying and perceptions of teaching. Powerful learning environments: Unravelling basic components and dimensions, 89-107.

Entwistle, N., \& Ramsden, P. (2015). Understanding Student Learning (Routledge Revivals). Routledge.

Entwistle, N., \& Tait, H. (1995). Approaches to studying and perceptions of the learning environment across disciplines. New directions for teaching and learning, 1995(64), 93103. https://doi.org/10.1002/tl.37219956413

Lindblom-Ylänne, S. (1999). Studying in a traditonal medical curriculum-study success, orientations to studying and problems that arise. Helsinki Univ. Printing House.

Marton, F., \& Säljö, R. (1976). On qualitative differences in learning: I-Outcome and process. British journal of educational psychology, 46(1), 4-11. https://doi.org/10.1111/j.2044-8279.1976.tb02980.x

Parpala, A., Lindblom-Ylänne, S., Komulainen, E., Litmanen, T., \& Hirsto, L. (2010). Students' approaches to learning and their experiences of the teaching-learning environment in different disciplines. British Journal of Educational Psychology, 80(2), 269-282. https://doi.org/10.1348/000709909X476946

Parpala, A., Lindblom-Ylänne, S., Komulainen, E., \& Entwistle, N. (2013). Assessing students' experiences of teaching-learning environments and approaches to learning: Validation of a questionnaire in different countries and varying contexts. Learning Environments Research, 16(2), 201-215. https://doi.org/10.1007/s10984-013-9128-8 


\section{Macrothink}

Pintrich, P. R. (1988). A process-oriented view of student motivation and cognition. New $\begin{array}{llrl}\text { directions for institutional research, 1988(57), 65-79. } & \text {. }\end{array}$ https://doi.org/10.1002/ir.37019885707

Pintrich, P. R. (1988). Student learning and college teaching. New directions for teaching and learning, 1988(33), 71-86. https://doi.org/10.1002/t1.37219883308

Prosser, M., \& Trigwell, K. (1999). Understanding learning and teaching: The experience in higher education. McGraw-Hill Education (UK).

Richardson, J. T. (2005). Students' approaches to learning and teachers' approaches to teaching in higher education. Educational Psychology, 25(6), 673-680. https://doi.org/10.1080/01443410500344720

Richardson, J. C., \& Newby, T. (2006). The role of students' cognitive engagement in online learning. The American Journal of Distance Education, 20(1), 23-37. https://doi.org/10.1207/s15389286ajde2001_3

Rytkönen, H., Parpala, A., Lindblom-Ylänne, S., Virtanen, V., \& Postareff, L. (2012). Factors affecting bioscience students' academic achievement. Instructional Science, 40(2), 241-256. https://doi.org/10.1007/s11251-011-9176-3

Weinstein, C. E., \& Meyer, D. K. (1991). Cognitive learning strategies and college teaching. New directions for teaching and learning, 1991(45), 15-26. https://doi.org/10.1002/t1.37219914505

\section{Copyright Disclaimer}

Copyright for this article is retained by the author(s), with first publication rights granted to the journal.

This is an open-access article distributed under the terms and conditions of the Creative Commons Attribution license (http://creativecommons.org/licenses/by/3.0/). 